\title{
Correlation of Ventricular Arrhythmogenesis with Neuronal Remodeling of Cardiac Postganglionic Parasympathetic Neurons in the Late Stage of Heart Failure after Myocardial Infarction
}

\section{OPEN ACCESS}

Edited by:

Mathias Baumert,

University of Adelaide, Australia

Reviewed by:

Luca Carnevali,

University of Parma, Italy

Sachin Nayyar,

University Health Network, Canada

*Correspondence:

Yu-Long Li

yulongli@unmc.edu

Specialty section: This article was submitted to Autonomic Neuroscience, a section of the journal Frontiers in Neuroscience

Received: 19 February 2017 Accepted: 20 April 2017 Published: 08 May 2017

Citation:

Zhang D, Tu H, Wang C, Cao L, Muelleman RL, Wadman MC and Li Y-L (2017) Correlation of Ventricular Arrhythmogenesis with Neuronal Remodeling of Cardiac Postganglionic

Parasympathetic Neurons in the Late Stage of Heart Failure after Myocardial Infarction. Front. Neurosci. 11:252. doi: 10.3389/fnins.2017.00252

\begin{abstract}
Dongze Zhang ${ }^{1}$, Huiyin $\mathrm{Tu}^{1}$, Chaojun Wang ${ }^{1,2}$, Liang Cao ${ }^{1,3}$, Robert L. Muelleman ${ }^{1}$, Michael C. Wadman ${ }^{1}$ and Yu-Long Li, ${ }^{1, *}$

${ }^{1}$ Department of Emergency Medicine, University of Nebraska Medical Center, Omaha, NE, USA, ${ }^{2}$ Department of Cardiovascular Disease, The First Affiliated Hospital of Xi'an Jiaotong University, Xi'an, China, ${ }^{3}$ Department of Cardiac Surgery, Second Xiangya Hospital, Central South University, Changsha, China, ${ }^{4}$ Department of Cellular \& Integrative Physiology, University of Nebraska Medical Center, Omaha, NE, USA
\end{abstract}

Introduction: Ventricular arrhythmia is a major cause of sudden cardiac death in patients with chronic heart failure (CHF). Our recent study demonstrates that N-type $\mathrm{Ca}^{2+}$ currents in intracardiac ganglionic neurons are reduced in the late stage of CHF rats. Rat intracardiac ganglia are divided into the atrioventricular ganglion (AVG) and sinoatrial ganglion. Only AVG nerve terminals innervate the ventricular myocardium. In this study, we tested the correlation of electrical remodeling in AVG neurons with ventricular arrhythmogenesis in CHF rats.

Methods and Results: CHF was induced in male Sprague-Dawley rats by surgical ligation of the left coronary artery. The data from 24-h continuous radiotelemetry ECG recording in conscious rats showed that ventricular tachycardia/fibrillation (VTNF) occurred in 3 and 14-week CHF rats but not 8-week CHF rats. Additionally, as an index for vagal control of ventricular function, changes of left ventricular systolic pressure (LVSP)

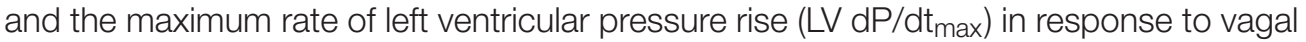
efferent nerve stimulation were blunted in 14-week CHF rats but not 3 or 8 -week CHF rats. Results from whole-cell patch clamp recording demonstrated that $\mathrm{N}$-type $\mathrm{Ca}^{2+}$ currents in AVG neurons began to decrease in 8-week CHF rats, and that there was also a significant decrease in 14-week CHF rats. Correlation analysis revealed that $\mathrm{N}$-type $\mathrm{Ca}^{2+}$ currents in AVG neurons negatively correlated with the cumulative duration of VTNF in 14-week CHF rats, whereas there was no correlation between $\mathrm{N}$-type $\mathrm{Ca}^{2+}$ currents in AVG neurons and the cumulative duration of VTNF in 3-week CHF.

Conclusion: Malignant ventricular arrhythmias mainly occur in the early and late stages of CHF. Electrical remodeling of AVG neurons highly correlates with the occurrence of ventricular arrhythmias in the late stage of CHF.

Keywords: chronic heart failure, electrocardiogram, intracardiac ganglia, $\mathrm{N}$-type calcium currents, parasympathetic, ventricular arrhythmia 


\section{INTRODUCTION}

Ventricular arrhythmia, including ventricular tachycardia and ventricular fibrillation (VT/VF), is the most common cause of sudden cardiac death (SCD) in patients with chronic heart failure (CHF) (Tomaselli and Zipes, 2004; Kolettis et al., 2015). Apart from structural and electrophysiological remodeling of the ventricle (Tomaselli and Zipes, 2004; Yamada et al., 2016), neuronal remodeling in the autonomic nervous system also plays a pivotal role in the development and maintenance of ventricular arrhythmias in patients with $\mathrm{CHF}$ and in $\mathrm{CHF}$ animal models (Ogawa et al., 2007; Vaseghi and Shivkumar, 2008; Shen and Zipes, 2014; Ajijola et al., 2015). It is well known that autonomic nervous dysfunction is associated with the development and progression of CHF (Fukuda et al., 2015). Much evidence has shown that sympathetic overactivation and withdrawal of parasympathetic activity serve as negative prognostic indicators for high mortality in CHF (Nolan et al., 1998; Frenneaux, 2004; Cygankiewicz et al., 2008; Hauptman et al., 2012; Shen and Zipes, 2014). Our recent study demonstrates that N-type $\mathrm{Ca}^{2+}$ currents and cell excitability of intracardiac ganglionic neurons are reduced in the late stage of CHF rats (Tu et al., 2014). Acetylcholine released from intracardiac ganglionic nerve terminals can bind to muscarinic acetylcholine receptors to regulate cardiac function (Thomas, 2011), and $\mathrm{Ca}^{2+}$ influx through voltage-gated $\mathrm{Ca}^{2+}$ channels is a key trigger for acetylcholine release (Akiyama and Yamazaki, 2000). Rat intracardiac ganglia are divided into the atrioventricular ganglion (AVG) and sinoatrial ganglion. The ventricular myocardium only receives projection of nerve terminals from the AVG (Pardini et al., 1987). These facts indicate that neuronal remodeling of the AVG is possibly involved in ventricular arrhythmogenesis in the CHF state.

Myocardial infarction (MI) is a major cause of CHF in the general population (Wolk et al., 1972; Spencer et al., 1999; Jhund and McMurray, 2008). However, progressive alterations of arrhythmic substrates and potential mechanisms involved in ventricular arrhythmogenesis in post-MI are still unknown. Using a rat model of CHF induced by surgical ligation of the left coronary artery, in this study we investigated the occurrence of ventricular arrhythmias and related arrhythmic substrates during the progression of CHF. We also tested whether electrical remodeling of AVG neurons is related to ventricular arrhythmogenesis during development of CHF.

\section{MATERIALS AND METHODS}

All experimental procedures were approved by the University of Nebraska Medical Center Institutional Animal Care and Use Committee and were carried out in accordance with the National Institutes of Health (NIH Publication No. 85-23, revised 1996) and the American Physiological Society's "Guides for the Care and Use of Laboratory Animals."

\section{Animal Model}

Study design, timeline, and interventions are shown in Figure 1. In the present study, 45 male Sprague-Dawley rats (6-7 weeks of age, $180-200 \mathrm{~g}$ ) were randomly assigned to one of two groups: sham $(n=15)$ and CHF $(n=30)$. All rats were housed two per cage under controlled temperature and humidity, a 12:12-h dark-light cycle, and provided water and rat chow ad libitum. CHF rats were anesthetized with $2 \%$ isoflurane (Butler Schein Animal Health, Dublin, OH, USA) for surgical ligation of the left coronary artery, and sham rats underwent the same surgery without coronary ligation, as described previously (Zhang et al., 2014, 2015). In the terminal experiment, a Millar pressure transducer was used to determine LV end-diastolic pressure (LVEDP) and systolic pressure (LVSP). A colorimetric technique was used to measure infarct size (see detail below). Rats with both LVEDP $>15 \mathrm{mmHg}$ and infarct size $>30 \%$ of the left ventricle were considered as CHF. Fifteen rats in CHF groups were excluded from the study, wherein 7 rats died within 1 week after coronary ligation, 5 rats died within 12-14 weeks after coronary ligation, and 3 rats were not considered as CHF due to insufficient LVEDP and/or infarct size. The cause of animal deaths is not clear in the present study because we did not perform measurement of the ECG and cardiac function in those dead rats.

\section{Implantation of the ECG Telemeter and Labeling of AVG Neurons}

Implantation of the ECG telemeter (Millar Instruments, Houston, TX, USA) was performed as described previously (Opitz et al., 1995; Baltogiannis et al., 2005; Shiba et al., 2012). As shown in Figure 1, on the day following 2, 7, or 13 weeks of coronary ligation (CHF groups) or the same surgery without coronary ligation (sham groups), rats were anesthetized with $2 \%$ isoflurane (Butler Schein Animal Health, Dublin, OH, USA), and skin was shaved and sterilized. After laparotomy was performed at the Linea Alba (abdomen), an ECG transmitter was placed into the abdominal cavity and secured to the abdominal wall at the best position for battery recharging and signal communication. In accordance with the Millar User Manual for ECG recording, bipolar electrodes were tunneled subcutaneously. The negative electrode was secured in the upper sternal midline and the positive electrode was attached to the underlying tissue near the left side of the xiphoid process. To reduce electrical noise during ECG recording, electrodes were kept together and run alongside each other as far as practical. All incisions were sutured in two layers. ECG recording was performed after 1 week recovery.

Although the ventricular myocardium only receives projection of nerve terminals from the AVG (Pardini et al., 1987), it is possible that the AVG also innervates other parts of the heart. To explore the relationship between parasympathetic activity and ventricular arrhythmia, we used a transported flourescent dye (red color DiI) to retrograde-label AVG neurons projecting to the ventricular myocardium. After implantation of the ECG telemeter was completed, a left thoracotomy was performed in the fourth intercostal space. Eight injections $(2 \mu 1$ DiI for each injection) were made subepicardially into the left ventricle, using a fine-tipped glass micropipette connected to a microinjector (Nanoliter 2000, WPI, Sarasota, FL, USA; Pardini et al., 1987). The surgical incision was closed and terminal experiments were performed at least 1 week after surgery, to allow the dye to diffuse to the neurons. 

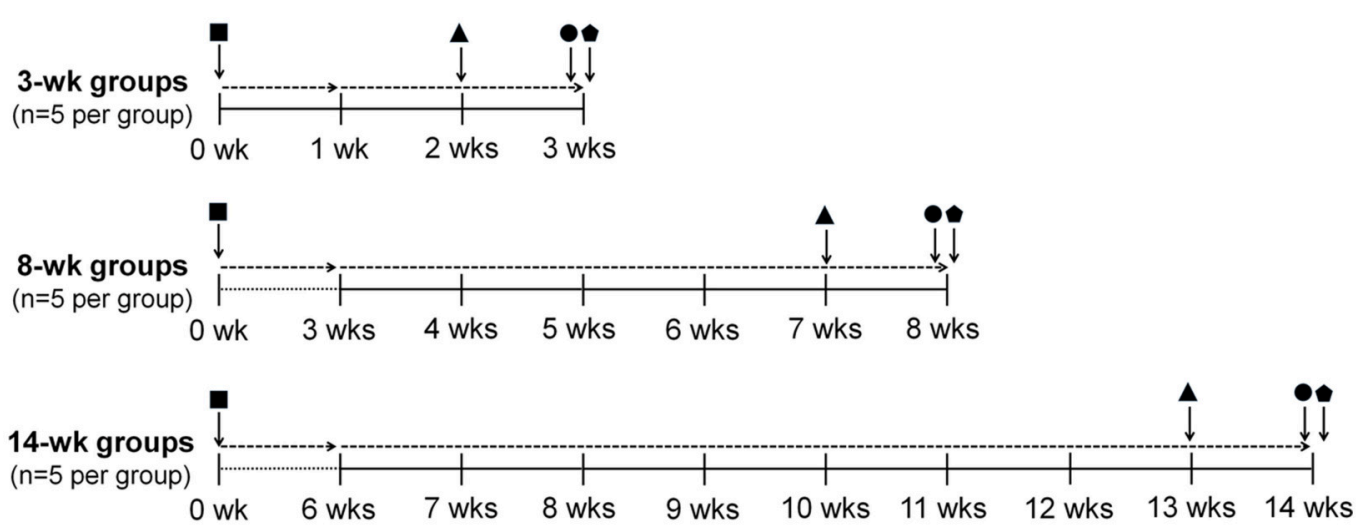

- Left coronary ligation for $\mathrm{CHF}$ rats or sham surgery for sham rats

$\Delta$ Implantation of ECG telemeter \& Labeling of AVG neurons

- 24-hour ECG recording in conscious rats

- Terminal experiments including measurement for inducibility of ventricular arrhythmia, measurement for vagal control of ventricular function, hemodynamic and morphological measurements, and patch-clamp recording for $\mathrm{N}$-type $\mathrm{Ca}^{2+}$ currents

FIGURE 1 | Schematic diagram illustrating study design, timeline and interventions. Chronic heart failure (CHF) model was induced by surgical ligation of the left coronary artery in rats. Sham rats underwent the same surgery without left coronary ligation. Implantation of the ECG telemeter and labeling of atrioventricular ganglion (AVG) neurons were performed on the day following 2, 7, or 13 weeks after left coronary ligation (CHF groups) or same surgery (Sham groups). One week after implantation of the ECG telemeter, ECG signals were continuously acquired for $24 \mathrm{~h}$ in conscious rats. Terminal experiments including measurement of inducibility of ventricular arrhythmia, measurement of vagal control of ventricular function, hemodynamic and morphological measurements, and patch-clamp recording for $\mathrm{N}$-type $\mathrm{Ca}^{2+}$ currents were performed at 3, 8, and 14 weeks after left coronary ligation (CHF groups) or sham surgery (Sham groups), respectively.

\section{ECG Recording in Conscious Rats}

One week after implantation of the ECG telemeter, rats were placed on a SmartPad receiver (Millar Instruments, Houston, TX, USA). For quantification of ventricular arrhythmic events, 24-h continuous ECG signals were acquired in unrestrained, conscious rats. Real-time ECG signals were digitalized and analyzed by PowerLab 8/30 Data Acquisition System with LabChart 7 software and ECG analysis module (ADInstruments, Colorado Springs, CO, USA). The number of premature ventricular contractions (PVCs) and cumulative duration of VT/VFs were counted manually during 24-h continuous ECG recording. VT was defined as PVCs lasting $\geq 4$ beats. VF was defined as rapid, irregular QRS complexes. QT and QTc intervals as well as dispersions $\left(\mathrm{QT}_{\mathrm{d}}\right.$ and $\left.\mathrm{QTc}_{\mathrm{d}}\right)$ were calculated from ECG recordings using Labchart software (Costa et al., 2008). QTc interval was calculated by Bazett's formula $(\mathrm{QT} \sqrt{R R}$, where RR is RR interval; Costa et al., 2008). As an index of the spatial dispersion of the ventricular repolarization, $\mathrm{QT}_{\mathrm{d}}$ and $\mathrm{QTc}_{\mathrm{d}}$ were calculated by equations: $\mathrm{QT}_{\mathrm{d}}=\mathrm{QT}_{\max }-\mathrm{QT}_{\min }$ and $\mathrm{QTc}_{\mathrm{d}}=\mathrm{QTc}_{\max }-\mathrm{QTc}_{\text {min }}$, where $\mathrm{QT}_{\max }$ and $\mathrm{QTc}_{\max }$ are the maximum QT interval and the maximum QTc interval; $\mathrm{QT}_{\min }$ and $\mathrm{QTc}_{\min }$ are the minimum $\mathrm{QT}$ interval and the minimum QTc interval (Costa et al., 2008). T-peak to T-end interval (Tpe), another marker of transmural dispersion of the ventricular repolarization, was calculated to serve as an ECG marker of ventricular arrhythmia (Yan et al., 2003; Antzelevitch, 2007; Yagishita et al., 2015).

\section{Measurement of Inducibility of Ventricular Tachyarrhythmia in Anesthetized Rats}

One day after radiotelemetry ECG recording, rats were anesthetized $(800 \mathrm{mg} / \mathrm{kg}$ urethane combined with $40 \mathrm{mg} / \mathrm{kg}$ $\alpha$-chloralose, i.p.), and the trachea was cannulated to facilitate mechanical respiration. Animal body temperature was maintained at $37^{\circ} \mathrm{C}$ with an animal temperature controller (ATC 1000; World Precision Instruments, Sarasota, FL, USA). Surface lead-II ECG was recorded using subcutaneous electrodes connected to a biological amplifier (AD Instruments, Colorado Springs, CO, USA). A left thoracotomy was then performed in the fourth intercostal space. After the heart was visualized, the pericardium was carefully removed. A bipolar platinum stimulating electrode was placed on the right ventricular outflow tract for electrical stimulation (Kang et al., 2009). Programmed electrical stimulations (PES) were performed by a programmed electrical stimulator (Digital Pulse Generator 1831; WPI, USA) and an isolator (A320R Isostim Stimulator; WPI, USA). The pulse current output was set to a twice capture threshold and a 2 -ms pulse width. To determine the ventricular effective refractory period $(\mathrm{VERP})$, a train of eight stimuli $(8 \times \mathrm{S} 1)$ at a $120 \mathrm{~ms}$ cycle length was applied, followed by an extra stimulus (S2). Starting at $90 \mathrm{~ms}$, the $\mathrm{S} 1-\mathrm{S} 2$ interval was reduced in steps of 2 ms until the VERP was identified (Gui et al., 2013). Based on the VERP, a programmed stimulation protocol combined by single (S2), double (S3) or triple extra- stimulus (S4) after a train of eight stimulus $(8 \times \mathrm{S} 1)$ was designed to induce 
ventricular tachyarrhythmia as described previously (Kang et al., 2009; Shiba et al., 2012; Hong et al., 2014). The end point of ventricular pacing was induction of ventricular tachyarrhythmia. Ventricular tachyarrhythmia was considered as non-inducible when PES induced either no ventricular premature beats or self-terminated ventricular premature beats $<6$. Ventricular tachyarrhythmia was considered as nonsustained when it lasted $\leq 15$ beats and sustained when it lasted $>15$ beats before spontaneously terminating (Belichard et al., 1994; Nguyen et al., 1998).

Inducibility of ventricular tachyarrhythmia was quantified by a quotient of ventricular arrhythmic score as described previously (Nguyen et al., 1998; Kang et al., 2009): 0, non-inducible preparations; 1, nonsustained tachyarrhythmias induced with 3 extra-stimuli; 2, sustained tachyarrhythmias induced with 3 extra-stimuli; 3, non-sustained tachyarrhythmias induced with 2 extra-stimuli; 4, sustained tachyarrhythmias induced with 2 extra-stimuli; 5, non-sustained tachyarrhythmias induced with 1 extra-stimulus; 6 , sustained tachyarrhythmias induced with 1 extra-stimulus; 7 , tachyarrhythmias induced during a train of 8 stimuli $(8 \times \mathrm{S} 1)$ at a basic cycle length of $120 \mathrm{~ms} ; 8$, the heart stopped before the PES.

\section{Measurement of Hemodynamics and Vagal Control of Ventricular Function}

After inducibility of ventricular arrhythmia was detected, the left femoral artery was cannulated with a polyethylene-50 catheter for measurement of blood pressure. A Millar pressure transducer (SPR 524; size, 3.5-Fr; Millar Instruments, Houston, TX, USA) was slowly inserted into the right carotid artery and carefully advanced to the left ventricle for measurement of left ventricular systolic pressure (LVSP), the maximum rate of left ventricular pressure rise $\left(\mathrm{LV} \mathrm{dP} / \mathrm{dt}_{\max }\right)$, and left ventricular end-diastolic pressure (LVEDP). Hemodynamic data were recorded by PowerLab 8/30 Data Acquisition System with LabChart 7 software (ADInstruments, Colorado Springs, CO, USA). Then, bilateral cervical vagal nerves, sympathetic nerves, and aortic depressor nerves (an afferent branch of the vagal nerve innervating the aortic arch and thoracic aorta) were isolated and transected to avoid influence of the arterial baroreflex. Because we found that response of LVSP to left vagal efferent nerve stimulation was markedly stronger than that to right vagal efferent nerve stimulation, the peripheral end of the left vagal nerve was placed on a bipolar stimulating electrode for vagal efferent nerve stimulation. Left vagal efferent nerve stimulation was applied by a Grass $\$ 9$ stimulator (Grass instruments, Quincy, MA, USA) with $10 \mathrm{~s}$ of constant-frequency stimulation $(0.1 \mathrm{~ms}$ pulse duration and intensity of $7.5 \mathrm{~V}$ at $1-100 \mathrm{~Hz}$ ). As the index of vagal control of ventricular function, changes of LVSP and $\mathrm{LV} \mathrm{dP} / \mathrm{dt}_{\max }$ in response to different frequencies of left vagal efferent nerve stimulation were recorded by PowerLab 8/30 data acquisition system with LabChart 7 software (ADInstruments, Colorado Springs, CO, USA).

\section{Morphological Measurements}

After in-vivo experiments were performed, the rat heart was removed to measure infarct size. A digital image of the left ventricle was captured by a digital camera (Canon, Japan). Infarct size was determined using a colorimetric technique coupled to a computerized planimetric analysis (Adobe Photoshop CS5 Extended). The percentage of infarct area to whole left ventricle was quantified using Adobe Photoshop CS5 Extended (Adobe Systems Incorporated, CA).

\section{Isolation of AVG Neurons and Whole Cell Patch-Clamp Recording for $\mathrm{Ca}^{2+}$ Currents}

After in-vivo experiments were performed, the AVG, located in a white color epicardial adipose pad at the junction of inferior pulmonary veins and left atrium, was exposed. AVG neurons were isolated by two-step enzymatic digestion protocol, as described previously (Liu et al., 2012; Tu et al., 2014). Briefly, the AVG was minced with microscissors and incubated with a modified Tyrode's solution containing $0.1 \%$ collagenase and $0.1 \%$ trypsin for $30 \mathrm{~min}$ at $37^{\circ} \mathrm{C}$. The tissue was then transferred to a modified Tyrode's solution containing $0.2 \%$ collagenase and $0.5 \%$ bovine serum albumin for $30 \mathrm{~min}$ of incubation at $37^{\circ} \mathrm{C}$. The isolated neurons were cultured at $37^{\circ} \mathrm{C}$ in a humidified atmosphere of $95 \%$ air-5\% $\mathrm{CO}_{2}$ for $4-8 \mathrm{~h}$ before patch-clamp experiments.

Voltage-gated $\mathrm{Ca}^{2+}$ currents were recorded only in DiIlabeled AVG neurons (ventricular vagal neurons) by the whole cell patch-clamp technique using an Axopatch 200B patch-clamp amplifier (Axon Instruments; Tu et al., 2014). Resistance of the patch pipette was 4-6 M $\Omega$ when filled with the following solution (in $\mathrm{mM}$ ): $120 \mathrm{CsCl}, 1 \mathrm{CaCl} 2,40$ HEPES, 11 EGTA, 4 MgATP, 0.3 Tris-GTP, 14 creatine phosphate, and 0.1 leupeptin ( $\mathrm{pH} 7.3$; 305 mosM). The extracellular solution consisted of (in mM): 140 TEA-Cl, 5 BaCl2, $1 \mathrm{MgCl}$, 10 HEPES, 0.001 TTX, 2 4-AP, and 10 glucose $(\mathrm{pH} 7.4 ; 310$ mosM). Series resistance of 5-13 M $\Omega$ was electronically compensated at $30-80 \%$. Junction potential was calculated to be $+7.9 \mathrm{mV}$ using the P-clamp 10.2 program (Axon Instruments), and all values of membrane potential given throughout were corrected using this value. Current traces were sampled at $10 \mathrm{kHz}$ and filtered at $5 \mathrm{kHz}$. The holding potential was $-80 \mathrm{mV}$ and current-voltage $(\mathrm{I}-\mathrm{V})$ relationships were elicited by $5-\mathrm{mV}$ step increments to potentials between -60 and $60 \mathrm{mV}$ for $500 \mathrm{~ms}$. Peak currents were measured for each test potential, and current density was calculated by dividing peak current by cell membrane capacitance. The P-clamp 10.2 program (Axon Instruments) was used for data acquisition and analysis. All experiments were performed at room temperature $\left(22-24^{\circ} \mathrm{C}\right)$. In patch clamp experiments, $\omega$-conotoxin GVIA (Alomone Labs) was used to block $\mathrm{N}$-type $\mathrm{Ca}^{2+}$ channels. Based on the previous study, the concentration of $\omega$-conotoxin GVIA $(1 \mu \mathrm{M})$ used in the present study is a saturating concentration for inhibiting $\mathrm{N}$-type $\mathrm{Ca}^{2+}$ channels (Jeong and Wurster, 1997; Tu et al., 2014).

\section{Statistical Analysis}

All data are presented as means \pm SEM. SigmaPlot 12 was used for data analysis. Statistical significance was determined by a two-way ANOVA with a post-hoc Bonferroni test for multi group comparison, a Fisher exact test for the incidence of ventricular arrhythmias, and a spearman rank correlation 
analysis for the correlation of ventricular arrhythmogenesis with $\mathrm{N}$-type $\mathrm{Ca}^{2+}$ currents. Normal distribution of data was confirmed with the Kolmogorov-Smirov test and equal variance with Levene's test. Statistical significance was accepted when $p<0.05$.

\section{RESULTS}

\section{Hemodynamic and Morphological Characteristics in Sham and CHF Rats}

The hemodynamic and morphological characteristics from sham and CHF rats are summarized in Table 1. There was no significant difference in mean arterial pressure (MAP) between age-matched sham and CHF rats (Table 1). As the index of left

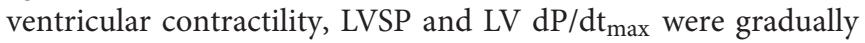
decreased from the early stage (3 weeks after MI, 3-week CHF) to the late stage of CHF rats (14 weeks after MI, 14-week CHF), compared with age matched sham rats $(p<0.05$ vs. age-matched sham rats). LVEDP was also significantly elevated in 3,8 , and 14-week CHF rats. In CHF rats, a gross examination displayed a dense scar in the anterior ventricular wall and myocardial infarct size about $40 \%$ of the left ventricular area, regardless whether 3 , 8 , or 14 -week CHF rats were observed ( $p<0.05$ vs. age-matched sham rats).

\section{Spontaneous Ventricular Arrhythmias during the Development of Heart Failure in Conscious Rats}

Spontaneous ventricular arrhythmias during the progression of conscious CHF rats were monitored by radiotelemetry ECG recording (Figure 2). Neither PVCs nor VT/VF was observed in sham rats. Although all rats had PVCs in all stages of CHF (Figure 2B), the number of PVCs was markedly increased only in 3 and 14-week CHF rats (Figure 2C). Additionally, the incidence and cumulative duration of VT/VF calculated from 24-h continuous ECG recording were significantly raised in 3 and 14-week CHF rats, whereas there was nonoccurrence of VT/VF in 8-week CHF rats (Figures 2D,E). These results indicate that malignant ventricular arrhythmias mainly occur in both early and late stages of MI-induced CHF rats.

\section{ECG Analysis from Continuous Radiotelemetry ECG Recording in Conscious Sham and CHF Rats}

To determine whether ventricular arrhythmogenesis in both early and late stages of CHF rats was associated with heterogeneity of ventricular electrical activity, ECG markers of ventricular arrhythmogenesis, including $\mathrm{QT}, \mathrm{QTc}, \mathrm{QT}_{\mathrm{d}}, \mathrm{QTc}_{\mathrm{d}}$, and Tpe were evaluated in conscious sham and CHF rats. All ECG parameters (QT, QTc, $\mathrm{QT}_{\mathrm{d}}, \mathrm{QTc}_{\mathrm{d}}$, and $\mathrm{Tpe}$ ) were significantly prolonged in 3 and 14-week CHF rats, compared to age-matched sham rats (Figure 3). However, these ECG markers of ventricular arrhythmogenesis did not show marked changes in 8 -week CHF rats $(P>0.05$ vs. age-matched sham rats).

\section{Susceptibility to Ventricular Arrhythmias in Anesthetized Sham and CHF Rats}

In sham rats, ventricular arrhythmias were not induced by $\mathrm{S}_{1} \mathrm{~S}_{2} \mathrm{~S}_{3} \mathrm{~S}_{4}$ programmed stimulation. Inducibility quotient of ventricular arrhythmias was zero in sham rats (Figure 4). In 3 and 14-week CHF rats, $100 \%$ (5/5) of the rats had PES-induced VT/VF, and inducibility quotient of ventricular arrhythmias was $3.6 \pm 0.9$ and $5.2 \pm 0.7$, respectively $(p<0.05$ vs. agematched sham rats). In 8 -week CHF rats, inducibility quotient of ventricular arrhythmias was $0.6 \pm 0.4(p>0.05$ vs. age-matched sham rats), although PES-induced VT/VF occurred in $40 \%(2 / 5)$ of the rats ( $p<0.05$ vs. age-matched sham rats, Figure 4$)$. These data further confirm that malignant ventricular arrhythmias readily occur in the early and late stages of MI-induced CHF rats.

\section{Changes in Vagal Control of the Ventricle during the Development of CHF}

Activation of the vagal efferent nerve results in negative inotropic effects in the ventricle, which serves as an index for ventricular response to vagal stimulation. Changes of the LVSP and LV $\mathrm{dP} / \mathrm{dt}_{\max }$ in response to different frequencies of vagal efferent nerve stimulation were markedly blunted in 14-week CHF rats, compared to age-matched sham rats ( $p<0.05$, Figure 5). However, there were no significant changes in these parameters in 3 and 8 -week CHF rats ( $p>0.05$ vs. age-matched sham rats, Figure 5).

TABLE 1 | Hemodynamic and morphological characteristics in anesthetized sham and CHF rats.

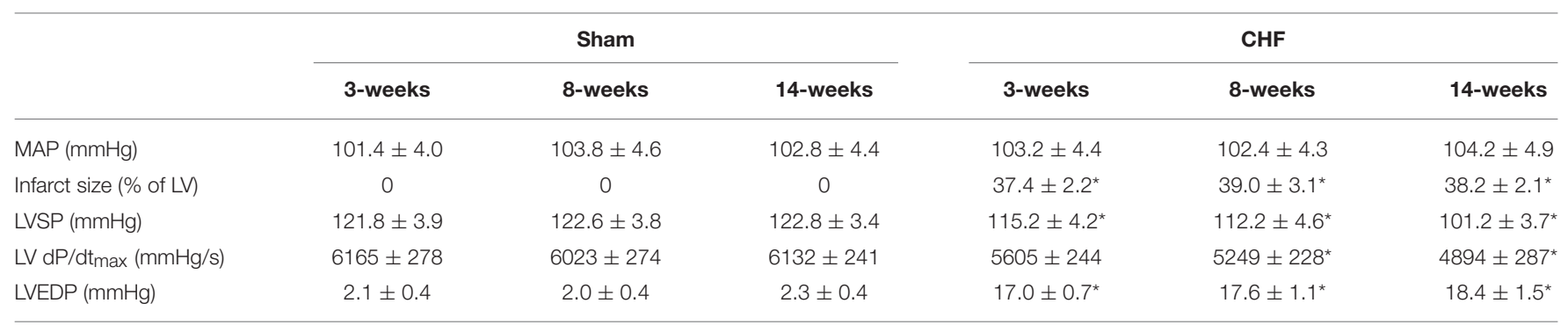

CHF, chronic heart failure; MAP, mean arterial pressure; LVSP, left ventricular systolic pressure; $L V d P / d t_{\text {max }}$, the maximum rate of left ventricular pressure rise; $L V E D P$, left ventricular end-diastolic pressure. Data are means $\pm S E M ; n=5$ in each group. ${ }^{*} P<0.05$ vs. age-matched sham rats. 
A
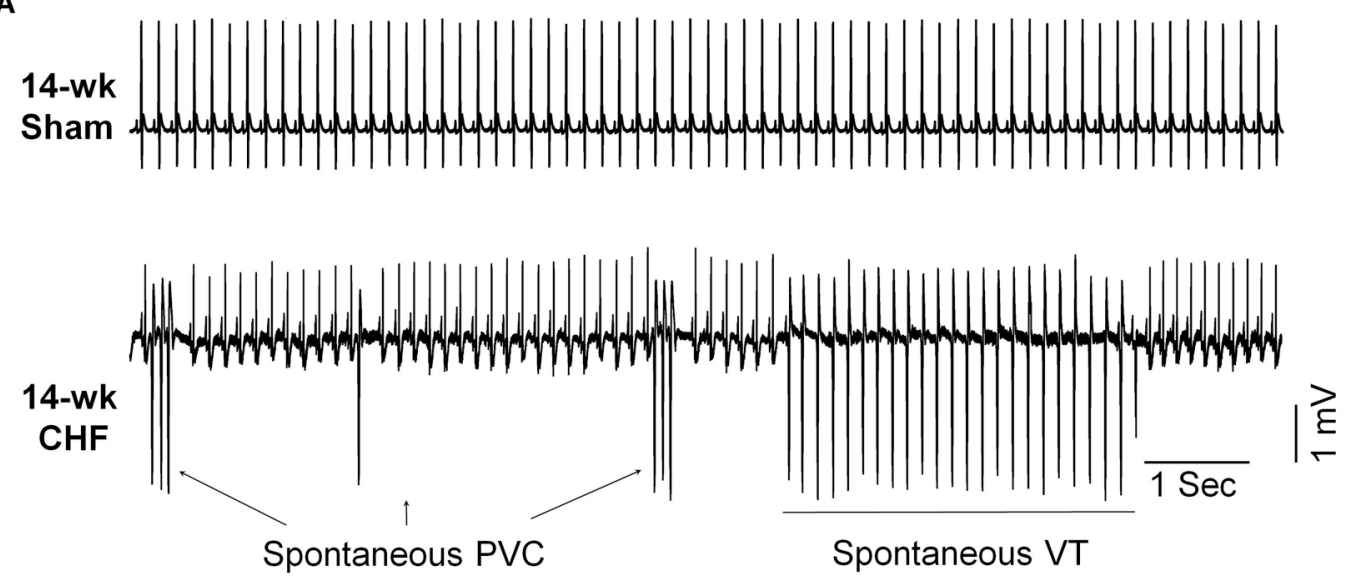

B

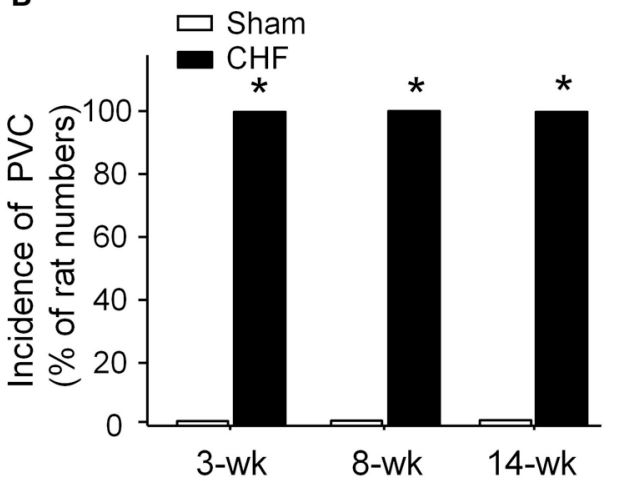

C

D
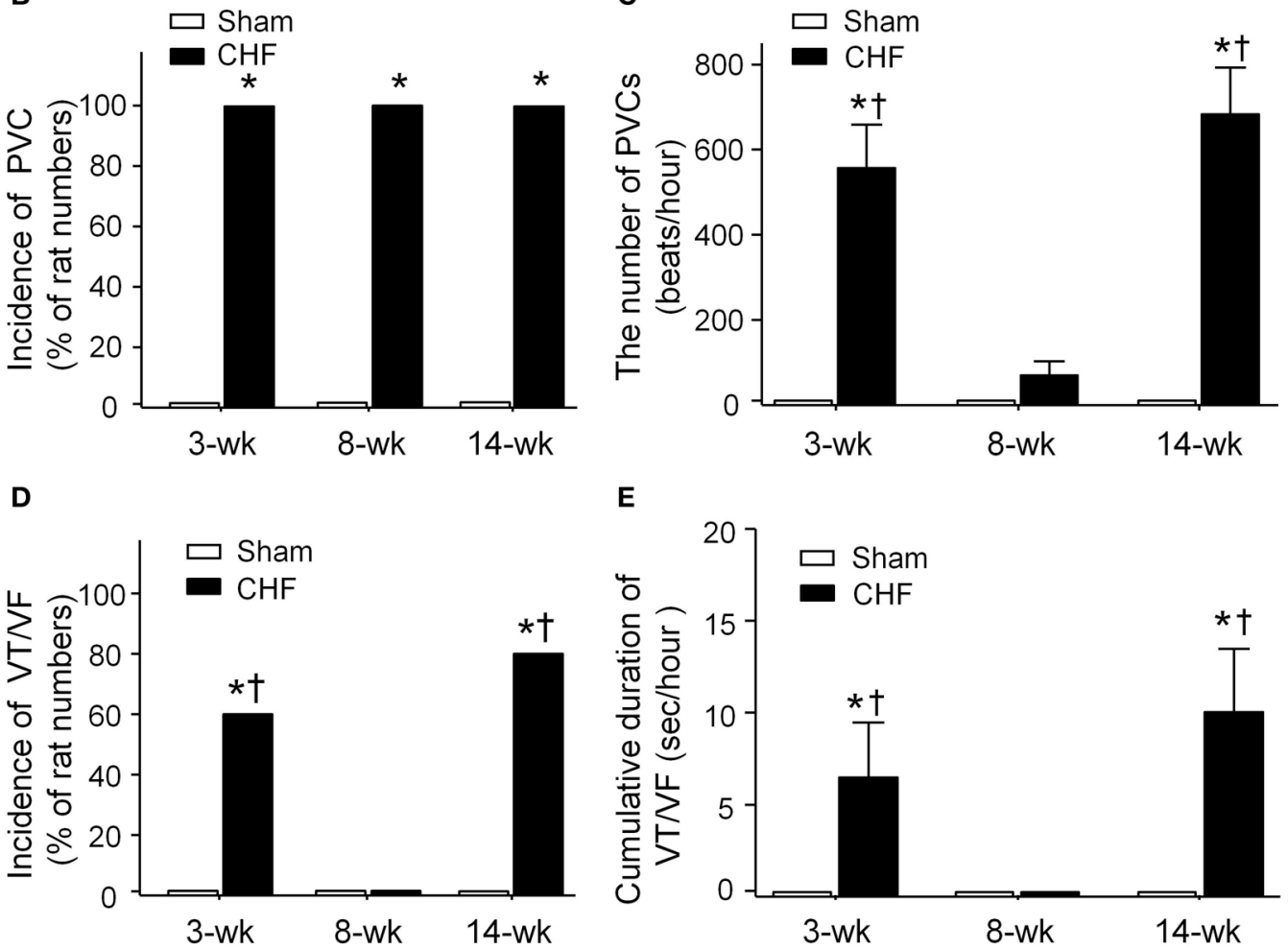

E

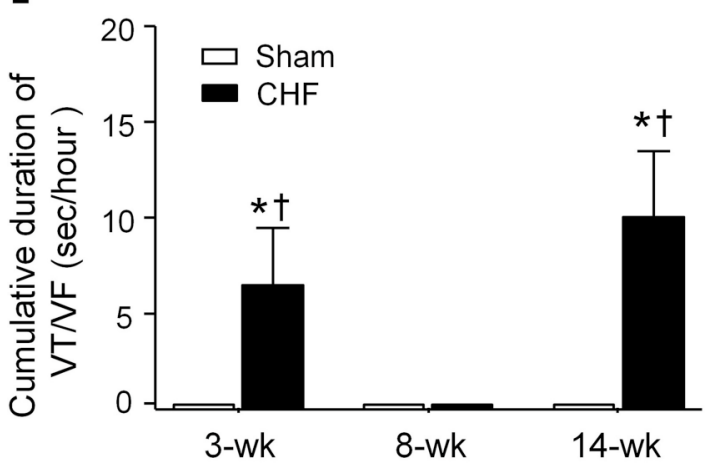

FIGURE 2 | Data for spontaneous arrhythmias obtained from 24-h continuous telemetry ECG recording in conscious sham and CHF rats.

(A) Representative ECG images showing ventricular arrhythmias including spontaneous premature ventricular contractions (PVCs) and ventricular tachycardia (VT) occurred in the late stage of CHF rat (14-week CHF). (B,C) Incidence and the number of PVCs in 3, 8, and 14-week sham and CHF rats. (D,E) Incidence and cumulative duration of VTNF in 3, 8, and 14-week sham and CHF rats. Data are mean $\pm \mathrm{SEM} ; n=5$ rats in each group. ${ }^{\star} P<0.05$ vs. age-matched sham rats; ${ }^{\dagger} p<0.05$ vs. 8-week CHF rats.

\section{$\mathrm{N}$-type $\mathrm{Ca}^{2+}$ Currents in AVG Neurons from Sham and CHF Rats}

Voltage-gated $\mathrm{Ca}^{2+}$ currents in DiI-labeled AVG neurons (ventricular vagal neurons) were recorded by whole-cell patchclamp technique. A specific $\mathrm{N}$-type $\mathrm{Ca}^{2+}$ channel blocker $(1 \mu \mathrm{M}$ $\omega$-conotoxin GVIA) was used to separate $\mathrm{N}$-type $\mathrm{Ca}^{2+}$ currents from total $\mathrm{Ca}^{2+}$ currents. N-type $\mathrm{Ca}^{2+}$ currents were obtained by subtracting $\mathrm{Ca}^{2+}$ currents under treatment of $\omega$-conotoxin GVIA from total $\mathrm{Ca}^{2+}$ currents (Figure 6A). There was no significant alteration in $\mathrm{N}$-type $\mathrm{Ca}^{2+}$ currents in AVG neurons from 3 and 8-week CHF rats, compared to age-matched sham rats $(p>0.05$, Figure 6B). Fourteen-week CHF significantly decreased $\mathrm{N}$-type $\mathrm{Ca}^{2+}$ currents in AVG neurons $(p<0.05$ vs. age-matched sham rats, Figure 6). 

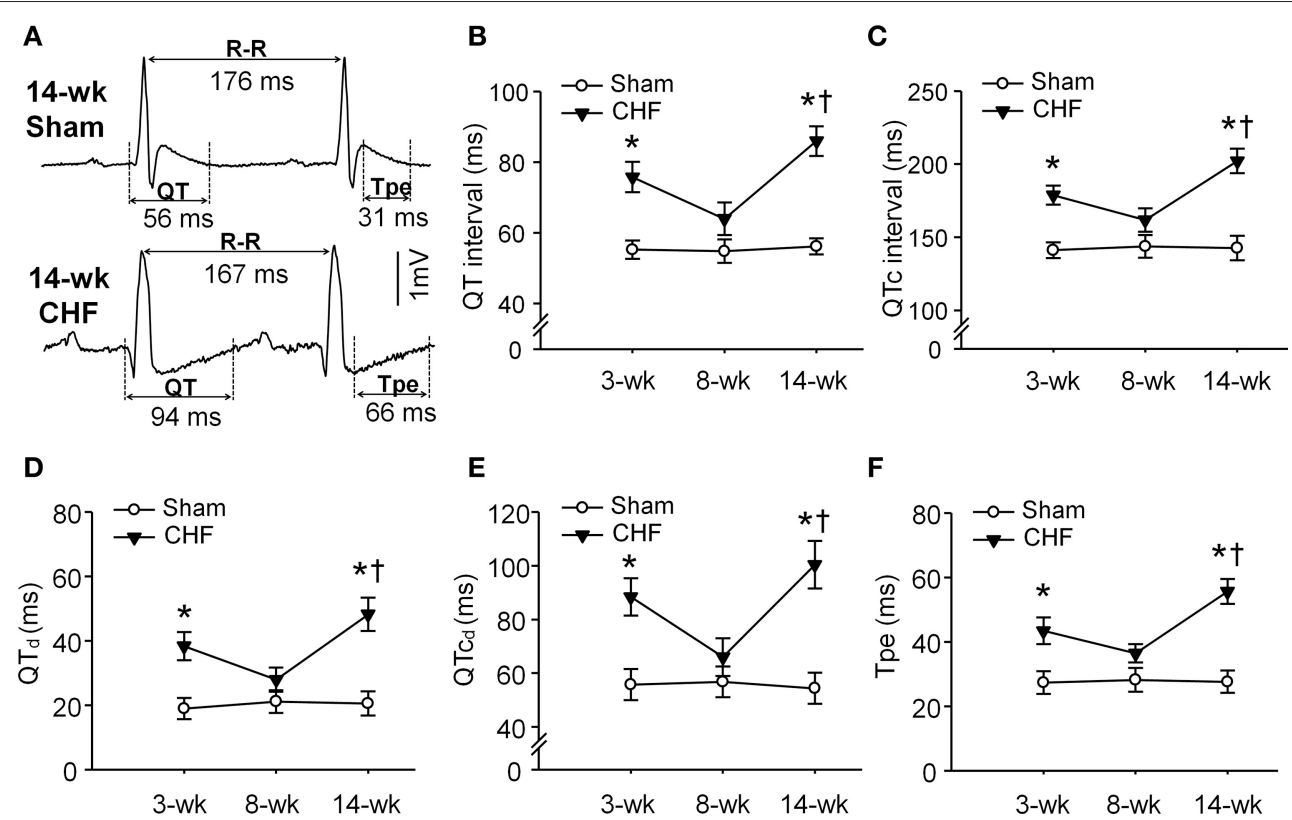

FIGURE 3 | Ventricular electrical activities calculated from 24-h continuous telemetry ECG recording in conscious sham and CHF rats.

(A) Representative lead-II ECG images illustrating prolongation of QT and T-peak to T-end interval (Tpe) in 14-week CHF rats. (B-F) Mean data for QT interval, corrected QT (QTc) interval, QT dispersions $\left(Q_{d}\right)$, QTc dispersions (QTc $d$ ), and Tpe in 3, 8, and 14-week sham and CHF rats. Data are mean \pm SEM; $n=5$ rats in each group. ${ }^{\star} P<0.05$ vs. age-matched sham rats; ${ }^{\dagger} p<0.05$ vs. 8 -week CHF rats.
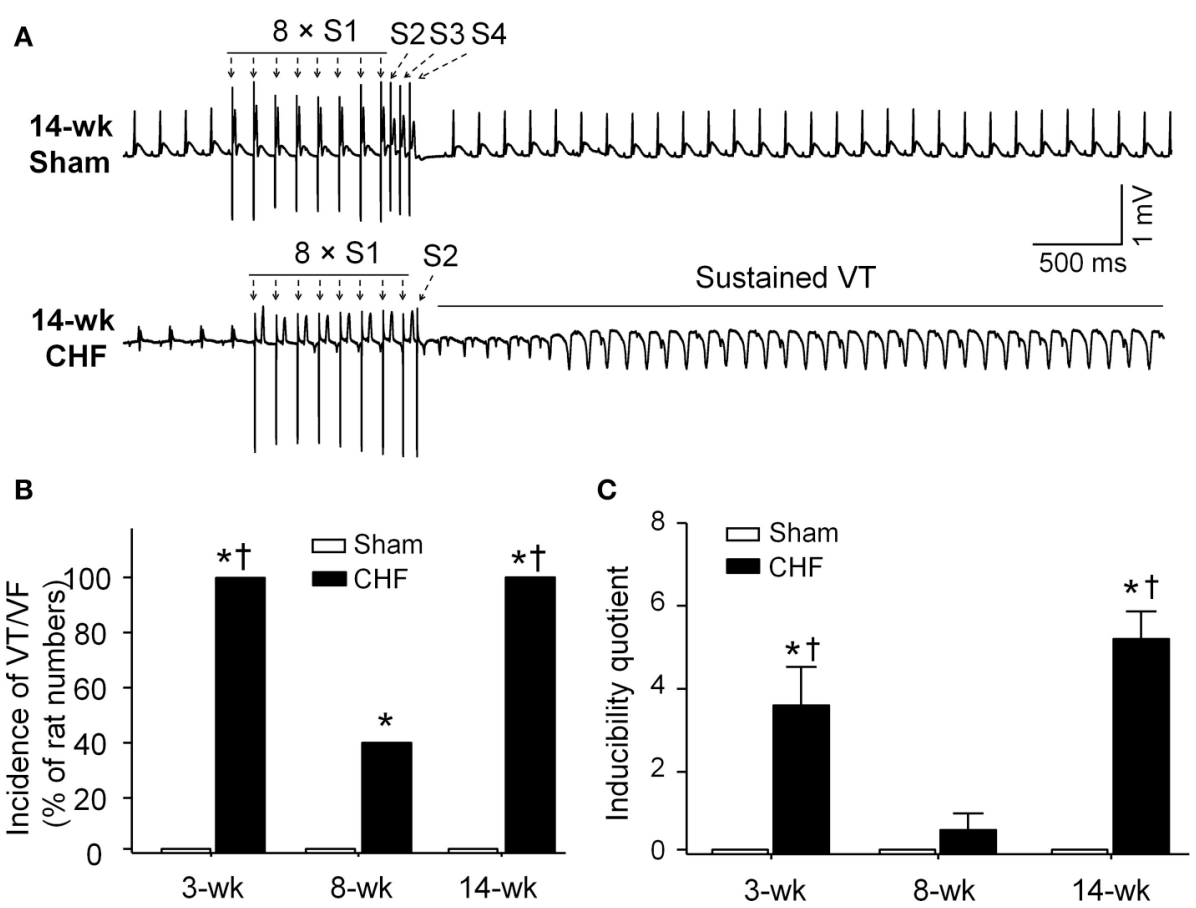

FIGURE 4 | Inducibility of ventricular tachyarrhythmia evoked by programed electrical stimulation (PES) in anesthetized sham and CHF rats.

(A) Representative ECG recordings showing nonoccurrence of PES-evoked ventricular arrhythmias in sham rat, and induction of VT evoked by PES in 14-week CHF rat. $(\mathbf{B}, \mathbf{C})$ Incidence and inducibility quotient of ventricular arrhythmias in 3,8 , and 14-week sham and CHF rats. Data are mean $\pm \mathrm{SEM} n=5$ rats in each group. ${ }^{\star} P<0.05$ vs. age-matched sham rats; ${ }^{\dagger} p<0.05$ vs. 8 -week $\mathrm{CHF}$ rats. 

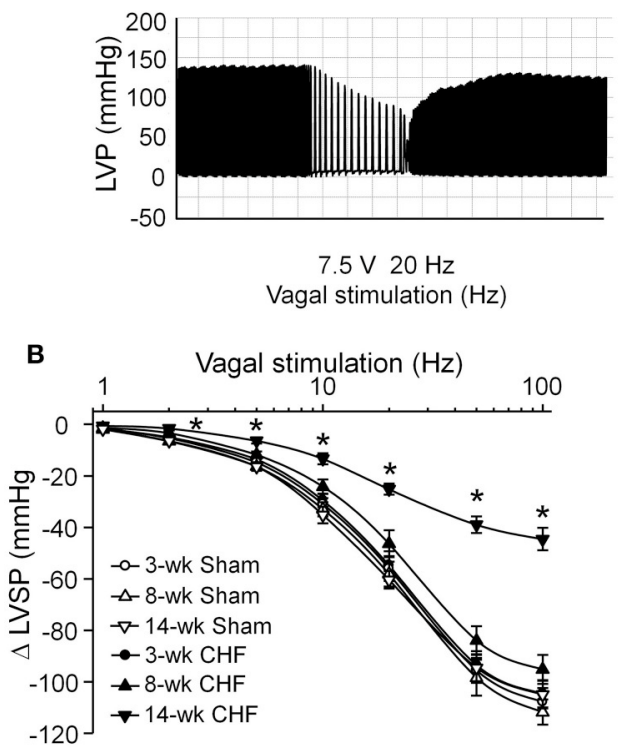

14-wk CHF

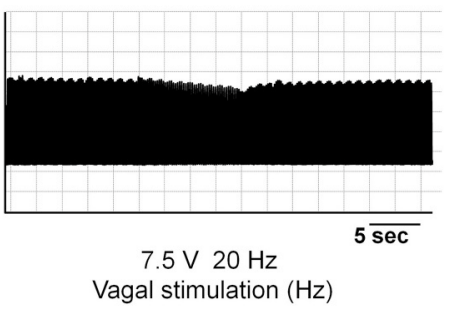

C

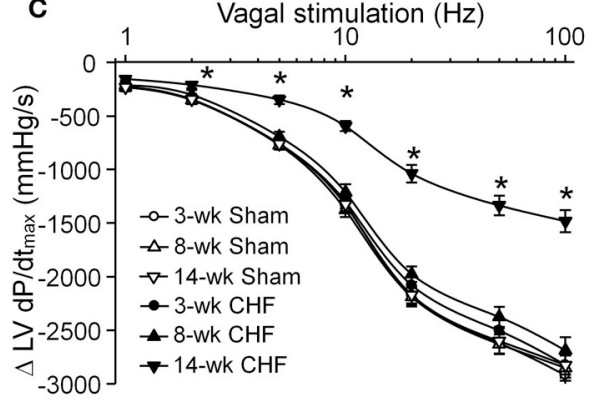

FIGURE 5 | Vagal control of ventricular function measured by changes of left ventricular systolic pressure (LVSP) in response to different frequencies of left vagal efferent nerve stimulation in anesthetized sham and CHF rats. (A) Representative recordings demonstrating change of LVSP in response to $20 \mathrm{~Hz}$ of left vagal efferent nerve stimulation in 14-week sham and CHF rats. (B,C) Quantitative data for changes of LVSP and LV dP/dtmax in response to different frequencies $(1-100 \mathrm{~Hz})$ of left vagal efferent nerve stimulation in 3, 8, and 14-week sham and CHF rats. Data are mean \pm SEM; $n=5$ rats in each group. ${ }^{*} P<0.05$ vs. age-matched sham rats.
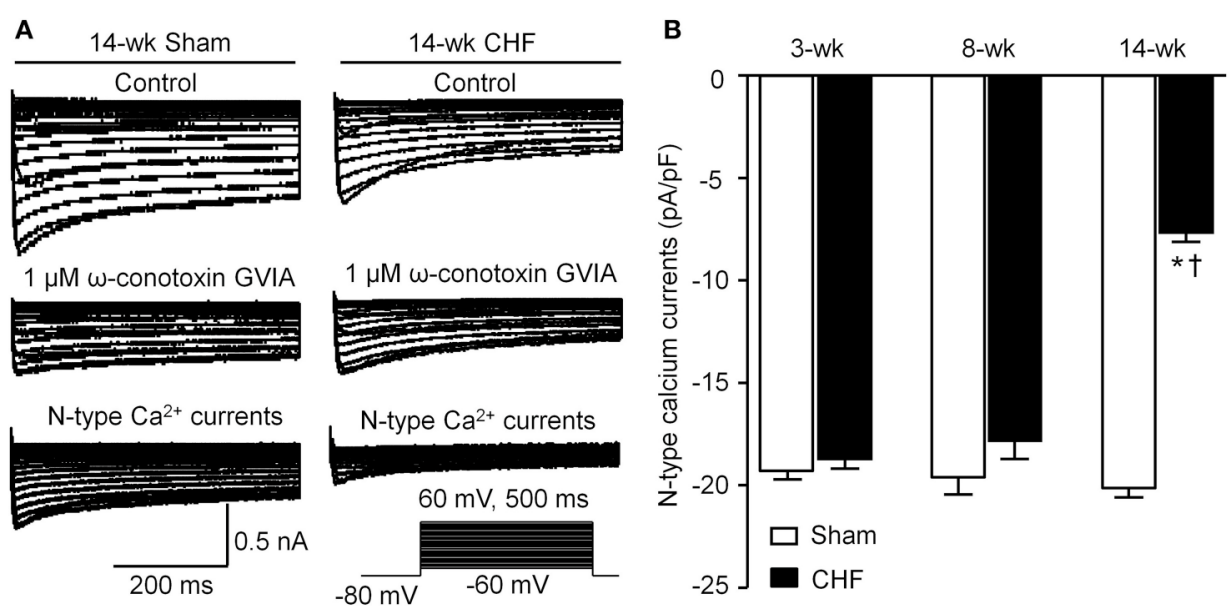

FIGURE 6 | N-type $\mathrm{Ca}^{2+}$ channel currents in Dil-labeled AVG neurons from sham and CHF rats. (A) Original recordings of $\mathrm{Ca}^{2+} \mathrm{Currents}$ in Dil-labeled AVG neurons from 14 -week sham and $\mathrm{CHF}$ rats. $\mathrm{N}$-type $\mathrm{Ca}^{2+}$ currents were obtained by subtracting $\mathrm{Ca}^{2+}$ currents under treatment of $\omega$-conotoxin $\mathrm{GVIA}$ from total $\mathrm{Ca}^{2+}$ currents. (B) Mean data for $\mathrm{N}$-type $\mathrm{Ca}^{2+}$ currents in Dil-labeled AVG neurons from 3, 8, and 14-week sham and CHF rats, measured in response to a test pulse from -80 to $-10 \mathrm{mV}$. Data are mean \pm SEM; $n=25$ neurons from 5 rats in each group. ${ }^{*} P<0.05$ vs. age-matched sham rats; ${ }^{\dagger} p<0.05$ vs. 3 and 8 -week $\mathrm{CHF}$ rats.

\section{Correlation of Ventricular \\ Arrhythmogenesis with $\mathrm{N}$-type $\mathrm{Ca}^{2+}$ Currents in AVG Neurons during the Progression of CHF}

Since malignant ventricular arrhythmias occurred in 3 and 14-week CHF rats, correlation between duration of VT/VF and
$\mathrm{N}$-type $\mathrm{Ca}^{2+}$ currents in AVG neurons was evaluated in 3 and 14-week CHF rats. As shown in Figure 7, N-type $\mathrm{Ca}^{2+}$ currents in AVG neurons negatively correlated with duration of VT/VF in 14 -week CHF rats $(R=-1.0, P=0.0167)$. However, there was no significant correlation between $\mathrm{N}$-type $\mathrm{Ca}^{2+}$ currents in AVG neurons and duration of VT/VF in 3-week CHF rats $(R=0.154$, $P=0.783)$. 


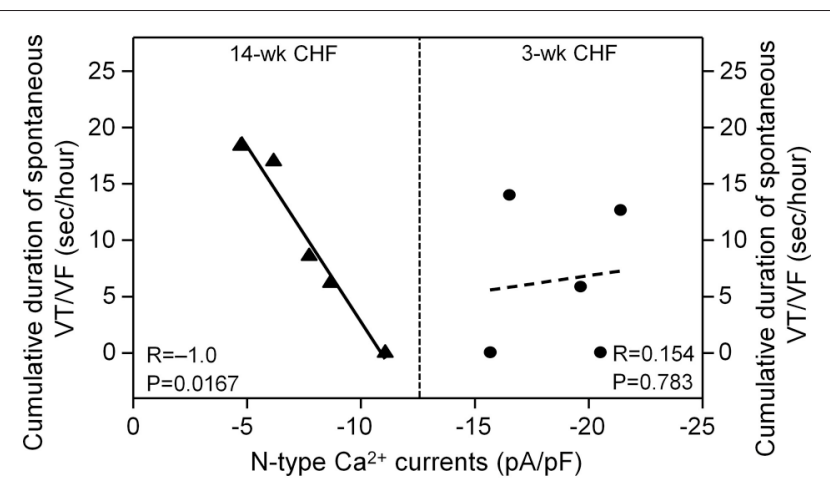

FIGURE 7 | Correlation between duration of spontaneous VT/VF and $\mathrm{N}$-type $\mathrm{Ca}^{2+}$ currents in AVG neurons in 3 and 14 -week CHF rats. $\mathrm{R}$ is the correlation coefficient. $N=25$ neurons from 5 rats in each group.

Statistical significance was accepted when $p<0.05$.

\section{DISCUSSION}

Our current study demonstrates the correlation between electrical remodeling of AVG neurons and ventricular arrhythmogenesis in different stages of CHF. ECG data obtained from both continuous telemetry recording in conscious rats and PES-induced inducibility of ventricular arrhythmias in anesthetized rats showed that malignant ventricular arrhythmias readily occurred in the early stage (3-week $\mathrm{CHF)}$ and late stage (14-week CHF) of CHF rats. Ventricular response to vagal nerve stimulation was markedly blunted in 14-week CHF rats but not in 3 and 8-week CHF rats. Whole-cell patch-clamp data showed that $\mathrm{N}$-type $\mathrm{Ca}^{2+}$ currents in AVG neurons were decreased in 14-week CHF rats. More importantly, the data from correlation analysis confirmed that electrical remodeling of AVG neurons negatively correlated with the occurrence of malignant ventricular arrhythmias in 14-week CHF rats but not in 3-week CHF rats. The above results suggest that decrease in N-type $\mathrm{Ca}^{2+}$ currents in AVG neurons might be associated with ventricular arrhythmias at late stage CHF.

Malignant ventricular arrhythmias remain a leading cause of SCD in patients with CHF (Tomaselli and Zipes, 2004; Kolettis et al., 2015). In the present study, malignant ventricular arrhythmias mainly occurred in early and late stage $\mathrm{CHF}$, whereas they did not occur in intermediate stage CHF (Figure 2). A hallmark of CHF is autonomic nervous dysfunction, including cardiac sympathetic overactivation and withdrawal of cardiac parasympathetic activity (Saul et al., 1988; Porter et al., 1990; Floras, 1993, 2009; Triposkiadis et al., 2009; Schwartz and De Ferrari, 2011). In addition to structural and electrophysiological remodeling of the left ventricle, growing evidence has demonstrated that sympathetic overactivation is thought to be an important ventricular arrhythmogenic mechanism during the progression of CHF, especially in the early stage of CHF (Meredith et al., 1991; Du et al., 1999; Aronson and Burger, 2003; Watson et al., 2006; Zipes and Rubart, 2006; Kolettis et al., 2015; Ajijola et al., 2017). However, we cannot ignore the role of attenuated cardiac parasympathetic activity in ventricular arrhythmogenesis in CHF. Some previous studies have shown that impairment of cardiac parasympathetic activation is associated with ventricular arrhythmia-related mortality in the CHF state (Corr and Gillis, 1974; Nolan et al., 1998; Frenneaux, 2004; Li et al., 2004; Zipes and Rubart, 2006; Cygankiewicz et al., 2008; Hauptman et al., 2012; Shen and Zipes, 2014). Our present study found that ventricular response to vagal nerve stimulation was attenuated in the late but not the early stage of CHF rats, although malignant ventricular arrhythmias occurred in both early and late stage CHF (Figures 2, 5). These results indicate that attenuated ventricular vagal activation might be associated with the occurrence of malignant ventricular arrhythmias in late stage CHF.

Cardiac vagal preganglionic fibers originate within the central nervous system at the level of the brainstem (nucleus ambiguous and nucleus tractus solitaries; Olshansky et al., 2008; Thomas, 2011). These vagal preganglionic efferent fibers extend to the intracardiac ganglia, located in cardiac fat pads, to form synapses with vagal postganglionic neurons (Olshansky et al., 2008; Thomas, 2011). Cardiac vagal postganglionic neurons located in the intracardiac ganglia provide local neural coordination independent of higher brain centers (Verrier and Antzelevitch, 2004; Cuevas, 2014). Our previous study demonstrated that a decrease in $\mathrm{N}$-type $\mathrm{Ca}^{2+}$ currents in intracardiac ganglionic neurons reduced the neuronal excitability of intracardiac ganglionic neurons and cardiac parasympathetic abnormality in late stage $\mathrm{CHF}$ ( $\mathrm{Tu}$ et al., 2014). Intracardiac ganglia are divided into the AVG and sinoatrial ganglion, and it is known that the ventricular myocardium only receives projection of nerve terminals from the AVG (Pardini et al., 1987). In the present study, we found that $\mathrm{N}$-type $\mathrm{Ca}^{2+}$ currents in AVG neurons negatively correlated with the occurrence of ventricular arrhythmias in late stage CHF (Figure 7). Although it is unclear how electrical remodeling of AVG neurons links to ventricular arrhythmogenesis in late stage CHF, many studies (Brack et al., 2013; Aiba et al., 2015; He et al., 2016) provide strong evidence in support of the pivotal anti-arrhythmic effect of parasympathetic activation. Vagal nerve stimulation inhibits ventricular arrhythmias through direct or indirect activation of muscarinic acetylcholine receptors (Brack et al., 2013; He et al., 2016). The parasympathetic activation induced by vagal nerve stimulation or treatment with exogenous acetylcholine suppresses the occurrence of ventricular arrhythmias and mitigates SCD in CHF (Sabbah, 2011; Aiba et al., 2015). Corr et al. reported that bilateral vagotomy or treatment with atropine (a specific muscarinic acetylcholine receptor antagonist) increases MI-induced SCD (Corr and Gillis, 1974). From the results of the present study, we considered that electrical remodeling such as reduced $\mathrm{N}$-type $\mathrm{Ca}^{2+}$ currents in AVG neurons might attenuate ventricular vagal activation and subsequently trigger ventricular arrhythmias in late stage CHF.

In the present study, first, QT and QTc intervals (the indices for total duration of the ventricular electrical activity) were markedly prolonged in the early and late stages of CHF rats (Figures 3B,C). Second, $\mathrm{QT}_{\mathrm{d}}$ and $\mathrm{QTc}_{\mathrm{d}}$ (the markers of spatial heterogeneity of ventricular repolarization) were increased in the early and late stages of CHF rats (Figures 3D,E). Third, a 
marker of transmural dispersion of ventricular repolarization, the Tpe, was prolonged in the early and late stage of $\mathrm{CHF}$ rats. (Figure 3F). Changes in these electrical activities represent the heterogeneity and dispersion of ventricular repolarization, and lead to malignant ventricular arrhythmias in CHF (Yan et al., 2003; Antzelevitch, 2007; Long et al., 2015; Yagishita et al., 2015; Xue et al., 2016). The action of acetylcholine binding with muscarinic acetylcholine receptors on ventricular ion channels is associated with alterations of these ventricular electrical activities (Rosenshtraukh et al., 1994; Zuberi et al., 2010; Machhada et al., 2015). The present study confirmed that electrical remodeling of AVG neurons negatively correlated with the occurrence of malignant ventricular arrhythmia in the late stage of CHF rats (Figure 7). Therefore, ventricular vagal dysfunction induced by electrical remodeling of AVG neurons may be related to changes in ventricular electrical activities and resultant malignant ventricular arrhythmias in late stage $\mathrm{CHF}$.

\section{LIMITATION OF THE STUDY}

There are two limitations in the present study. First, although our current study demonstrates the negative correlation of ventricular arrhythmogenesis with neuronal remodeling of AVG neurons in the late stage of CHF, we could not clarify whether the occurrence of ventricular arrhythmias in the late stage of CHF is totally or partially due to neuronal remodeling of AVG neurons. Mechanical/chemical AVG destruction in a control group of sham operation possibly destroys sympathetic efferent nerve fibers passing through the AVG, which limits us from performing this measurement. An alternative way is to decrease $\mathrm{N}$-type $\mathrm{Ca}^{2+}$ channels in sham AVG neurons using in-vivo lentiviral transfection of $\mathrm{N}$-type $\mathrm{Ca}^{2+}$ channel shRNA into sham AVG neurons. We will address this issue in our future study. Second, we didn't perform echocardiography measurement in

\section{REFERENCES}

Aiba, T., Noda, T., Hidaka, I., Inagaki, M., Katare, R. G., Ando, M., et al. (2015). Acetylcholine suppresses ventricular arrhythmias and improves conduction and connexin-43 properties during myocardial ischemia in isolated rabbit hearts. J. Cardiovasc. Electrophysiol. 26, 678-685. doi: 10.1111/jce.12663

Ajijola, O. A., Lux, R. L., Khahera, A., Kwon, O., Aliotta, E., Ennis, D. B., et al. (2017). Sympathetic modulation of electrical activation in normal and infarcted myocardium: implications for arrhythmogenesis. Am. J. Physiol. Heart Circ. Physiol. 312, H608-H621. doi: 10.1152/ajpheart.00575.2016

Ajijola, O. A., Yagishita, D., Reddy, N. K., Yamakawa, K., Vaseghi, M., Downs, A. M., et al. (2015). Remodeling of stellate ganglion neurons after spatially targeted myocardial infarction: neuropeptide and morphologic changes. Heart Rhythm 12, 1027-1035. doi: 10.1016/j.hrthm.2015.01.045

Akiyama, T., and Yamazaki, T. (2000). Adrenergic inhibition of endogenous acetylcholine release on postganglionic cardiac vagal nerve terminals. Cardiovasc. Res. 46, 531-538. doi: 10.1016/S0008-6363(00)00027-4

Antzelevitch, C. (2007). Heterogeneity and cardiac arrhythmias: an overview. Heart Rhythm 4, 964-972. doi: 10.1016/j.hrthm.2007.03.036

Aronson, D., and Burger, A. J. (2003). Neurohumoral activation and ventricular arrhythmias in patients with decompensated congestive heart failure: role of endothelin. Pacing Clin. Electrophysiol. 26, 703-710. doi: 10.1046/j.1460-9592.2003.00120.x

Baltogiannis, G. G., Tsalikakis, D. G., Mitsi, A. C., Hatzistergos, K. E., Elaiopoulos, D., Fotiadis, D. I., et al. (2005). Endothelin receptor-a blockade decreases the present study because the data from echocardiography were reported in many previous studies from other investigators and ourselves (Tu et al., 2010; Del et al., 2013; Wang et al., 2014; Becker et al., 2016; Collister et al., 2016). There is no significant difference in left ventricular ejection fraction at 26 weeks (Wang et al., 2014; Becker et al., 2016; Collister et al., 2016), 6-8 weeks (Tu et al., 2010), and 16 weeks after left coronary ligation (Del et al., 2013). In the present study, we used elevation in LVEDP to evaluate ventricular function in different stages of CHF. Like echocardiographic data, LVEDP was elevated almost to the same level in 3,8, and 14-week CHF rats (Table 1).

\section{CONCLUSION}

Our present study demonstrates that malignant ventricular arrhythmias mainly occur in the early and late stages of MI-induced CHF. Electrical remodeling in AVG neurons might be associated with ventricular vagal dysfunction, alterations of ventricular electrical activities, and malignant ventricular arrhythmias in the late stage of $\mathrm{CHF}$.

\section{AUTHOR CONTRIBUTIONS}

DZ and YL conceived and designed the experiments. DZ, HT, CW, LC, and YL performed the experiments and analyzed the data. YL, RM, and MW contributed reagents/materials/analysis tools. DZ, RM, MW, and YL wrote the paper.

\section{FUNDING}

This work was supported by American Heart Association (AHA) Grant-in-Aid (15GRANT24970002) to YL.

ventricular arrhythmias after myocardial infarction in rats. Cardiovasc. Res. 67, 647-654. doi: 10.1016/j.cardiores.2005.04.020

Becker, B. K., Tian, C., Zucker, I. H., and Wang, H. J. (2016). Influence of brainderived neurotrophic factor-tyrosine receptor kinase B signalling in the nucleus tractus solitarius on baroreflex sensitivity in rats with chronic heart failure. $J$ Physiol. 594, 5711-5725. doi: 10.1113/JP272318

Belichard, P., Savard, P., Cardinal, R., Nadeau, R., Gosselin, H., Paradis, P., et al. (1994). Markedly different effects on ventricular remodeling result in a decrease in inducibility of ventricular arrhythmias. J. Am. Coll. Cardiol. 23, 505-513. doi: 10.1016/0735-1097(94)90440-5

Brack, K. E., Winter, J., and Ng, G. A. (2013). Mechanisms underlying the autonomic modulation of ventricular fibrillation initiation-tentative prophylactic properties of vagus nerve stimulation on malignant arrhythmias in heart failure. Heart Fail. Rev. 18, 389-408. doi: 10.1007/s10741-012-9314-2

Collister, J. P., Hartnett, C., Mayerhofer, T., Nahey, D., Stauthammer, C., Kruger, M., et al. (2016). Overexpression of copper/zinc superoxide dismutase in the median preoptic nucleus improves cardiac function after myocardial infarction in the rat. Clin. Exp. Pharmacol. Physiol. 43, 960-966. doi: 10.1111/1440-1681.12607

Corr, P. B., and Gillis, R. A. (1974). Role of the vagus nerves in the cardiovascular changes induced by coronary occlusion. Circulation 49, 86-97. doi: 10.1161/01.CIR.49.1.86

Costa, E. C., Goncalves, A. A., Areas, M. A., and Morgabel, R. G. (2008). Effects of metformin on QT and QTc interval dispersion of diabetic rats. Arq. Bras. Cardiol. 90, 232-238. doi: 10.1590/S0066-782X2008000400004 
Cuevas, J. (2014). Molecular mechanisms of dysautonomia during heart failure. Focus on "Heart failure-induced changes of voltage-gated $\mathrm{Ca}^{2+}$ channels and cell excitability in rat cardiac postganglionic neurons." Am. J. Physiol. Cell. Physiol. 306, C121-C122. doi: 10.1152/ajpcell.00311.2013

Cygankiewicz, I., Zareba, W., Vazquez, R., Vallverdu, M., Gonzalez-Juanatey, J. R., Valdes, M., et al. (2008). Heart rate turbulence predicts all-cause mortality and sudden death in congestive heart failure patients. Heart Rhythm 5, 1095-1102. doi: 10.1016/j.hrthm.2008.04.017

Del, R. R., Marcus, N. J., and Schultz, H. D. (2013). Carotid chemoreceptor ablation improves survival in heart failure: rescuing autonomic control of cardiorespiratory function. J. Am. Coll. Cardiol. 62, 2422-2430. doi: 10.1016/j.jacc.2013.07.079

Du, X. J., Cox, H. S., Dart, A. M., and Esler, M. D. (1999). Sympathetic activation triggers ventricular arrhythmias in rat heart with chronic infarction and failure. Cardiovasc. Res. 43, 919-929. doi: 10.1016/S0008-6363(99)00139-X

Floras, J. S. (1993). Clinical aspects of sympathetic activation and parasympathetic withdrawal in heart failure. J. Am. Coll. Cardiol. 22, 72A-84A. doi: 10.1016/0735-1097(93)90466-e

Floras, J. S. (2009). Sympathetic nervous system activation in human heart failure: clinical implications of an updated model. J. Am. Coll. Cardiol. 54, 375-385. doi: 10.1016/j.jacc.2009.03.061

Frenneaux, M. P. (2004). Autonomic changes in patients with heart failure and in post-myocardial infarction patients. Heart 90, 1248-1255. doi: 10.1136/hrt.2003.026146

Fukuda, K., Kanazawa, H., Aizawa, Y., Ardell, J. L., and Shivkumar, K. (2015). Cardiac innervation and sudden cardiac death. Circ. Res. 116, 2005-2019. doi: 10.1161/CIRCRESAHA.116.304679

Gui, L., Bao, Z., Jia, Y., Qin, X., Cheng, Z. J., Zhu, J., et al. (2013). Ventricular tachyarrhythmias in rats with acute myocardial infarction involves activation of small-conductance $\mathrm{Ca}^{2+}$-activated $\mathrm{K}^{+}$channels. Am. J. Physiol. Heart Circ. Physiol. 304, H118-H130. doi: 10.1152/ajpheart.00820.2011

Hauptman, P. J., Schwartz, P. J., Gold, M. R., Borggrefe, M., Van Veldhuisen, D. J., Starling, R. C., et al. (2012). Rationale and study design of the increase of vagal tone in heart failure study: INOVATE-HF. Am. Heart J. 163, 954-962. doi: 10.1016/j.ahj.2012.03.021

He, B., Lu, Z., He, W., Huang, B., and Jiang, H. (2016). Autonomic modulation by electrical stimulation of the parasympathetic nervous system: an emerging intervention for cardiovascular diseases. Cardiovasc. Ther. 34, 167-171. doi: 10.1111/1755-5922.12179

Hong, T., Yang, H., Zhang, S. S., Cho, H. C., Kalashnikova, M., Sun, B., et al. (2014). Cardiac BIN1 folds T-tubule membrane, controlling ion flux and limiting arrhythmia. Nat. Med. 20, 624-632. doi: 10.1038/nm.3543

Jeong, S. W., and Wurster, R. D. (1997). Calcium channel currents in acutely dissociated intracardiac neurons from adult rats. J. Neurophysiol. 77, 1769-1778.

Jhund, P. S., and McMurray, J. J. (2008). Heart failure after acute myocardial infarction: a lost battle in the war on heart failure? Circulation 118, 2019-2021. doi: 10.1161/CIRCULATIONAHA.108.813493

Kang, C. S., Chen, C. C., Lin, C. C., Chang, N. C., and Lee, T. M. (2009). Effect of ATP-sensitive potassium channel agonists on sympathetic hyperinnervation in postinfarcted rat hearts. Am. J. Physiol. Heart. Circ. Physiol. 296, H1949-H1959. doi: 10.1152/ajpheart.00903.2008

Kolettis, T. M., Kontonika, M., Barka, E., Daskalopoulos, E. P., Baltogiannis, G. G., Tourmousoglou, C., et al. (2015). Central sympathetic activation and arrhythmogenesis during acute myocardial infarction: modulating effects of endothelin-B receptors. Front. Cardiovasc. Med. 2:6. doi: $10.3389 / \mathrm{fcvm} .2015 .00006$

Li, M., Zheng, C., Sato, T., Kawada, T., Sugimachi, M., and Sunagawa, K. (2004). Vagal nerve stimulation markedly improves long-term survival after chronic heart failure in rats. Circulation 109, 120-124. doi: 10.1161/01.CIR.0000105721.71640.DA

Liu, J., Tu, H., Zheng, H., Zhang, L., Tran, T. P., Muelleman, R. L., et al. (2012). Alterations of calcium channels and cell excitability in intracardiac ganglion neurons from type 2 diabetic rats. Am. J. Physiol. Cell. Physiol. 302, C1119-C1127. doi: 10.1152/ajpcell.00315.2011

Long, V. P. III., Bonilla, I. M., Vargas-Pinto, P., Nishijima, Y., Sridhar, A., Li, C., et al. (2015). Heart failure duration progressively modulates the arrhythmia substrate through structural and electrical remodeling. Life Sci. 123, 61-71. doi: $10.1016 /$ j.lfs.2014.12.024

Machhada, A., Ang, R., Ackland, G. L., Ninkina, N., Buchman, V. L., Lythgoe, M. F., et al. (2015). Control of ventricular excitability by neurons of the dorsal motor nucleus of the vagus nerve. Heart Rhythm. 12, 2285-2293. doi: 10.1016/j.hrthm.2015.06.005

Meredith, I. T., Broughton, A., Jennings, G. L., and Esler, M. D. (1991). Evidence of a selective increase in cardiac sympathetic activity in patients with sustained ventricular arrhythmias. N. Engl. J. Med. 325, 618-624. doi: 10.1056/NEJM199108293250905

Nguyen, T., El Salibi, E., and Rouleau, J. L. (1998). Postinfarction survival and inducibility of ventricular arrhythmias in the spontaneously hypertensive rat: effects of ramipril and hydralazine. Circulation 98, 2074-2080. doi: 10.1161/01.CIR.98.19.2074

Nolan, J., Batin, P. D., Andrews, R., Lindsay, S. J., Brooksby, P., Mullen, M., et al. (1998). Prospective study of heart rate variability and mortality in chronic heart failure: results of the United Kingdom heart failure evaluation and assessment of risk trial (UK-heart). Circulation 98, 1510-1516. doi: 10.1161/01.CIR.98.15.1510

Ogawa, M., Zhou, S., Tan, A. Y., Song, J., Gholmieh, G., Fishbein, M. C., et al. (2007). Left stellate ganglion and vagal nerve activity and cardiac arrhythmias in ambulatory dogs with pacing-induced congestive heart failure. J. Am. Coll. Cardiol. 50, 335-343. doi: 10.1016/j.jacc.2007.03.045

Olshansky, B., Sabbah, H. N., Hauptman, P. J., and Colucci, W. S. (2008). Parasympathetic nervous system and heart failure: pathophysiology and potential implications for therapy. Circulation 18, 863-871. doi: 10.1161/CIRCULATIONAHA.107.760405

Opitz, C. F., Mitchell, G. F., Pfeffer, M. A., and Pfeffer, J. M. (1995). Arrhythmias and death after coronary artery occlusion in the rat. Continuous telemetric ECG monitoring in conscious, untethered rats. Circulation 92, 253-261. doi: 10.1161/01.CIR.92.2.253

Pardini, B. J., Patel, K. P., Schmid, P. G., and Lund, D. D. (1987). Location, distribution and projections of intracardiac ganglion cells in the rat. J. Auton. Nerv. Syst. 20, 91-101. doi: 10.1016/0165-1838(87)90106-8

Porter, T. R., Eckberg, D. L., Fritsch, J. M., Rea, R. F., Beightol, L. A., Schmedtje, J. F., et al. (1990). Autonomic pathophysiology in heart failure patients. Sympathetic-cholinergic interrelations. J. Clin. Invest. 85, 1362-1371. doi: 10.1172/JCI114580

Rosenshtraukh, L., Danilo, P. Jr., Anyukhovsky, E. P., Steinberg, S. F., Rybin, V., Brittain-Valenti, K., et al. (1994). Mechanisms for vagal modulation of ventricular repolarization and of coronary occlusion-induced lethal arrhythmias in cats. Circ. Res. 75, 722-732. doi: 10.1161/01.RES.75.4.722

Sabbah, H. N. (2011). Electrical vagus nerve stimulation for the treatment of chronic heart failure. Cleve. Clin. J. Med. 78(Suppl. 1), S24-S29. doi: $10.3949 /$ ccjm.78.s1.04

Saul, J. P., Arai, Y., Berger, R. D., Lilly, L. S., Colucci, W. S., and Cohen, R. J. (1988). Assessment of autonomic regulation in chronic congestive heart failure by heart rate spectral analysis. Am. J. Cardiol. 61, 1292-1299. doi: 10.1016/0002-9149(88)91172-1

Schwartz, P. J., and De Ferrari, G. M. (2011). Sympathetic-parasympathetic interaction in health and disease: abnormalities and relevance in heart failure. Heart Fail. Rev. 16, 101-107. doi: 10.1007/s10741-010-9179-1

Shen, M. J., and Zipes, D. P. (2014). Role of the autonomic nervous system in modulating cardiac arrhythmias. Circ. Res. 114, 1004-1021. doi: 10.1161/CIRCRESAHA.113.302549

Shiba, Y., Fernandes, S., Zhu, W. Z., Filice, D., Muskheli, V., Kim, J., et al. (2012). Human ES-cell-derived cardiomyocytes electrically couple and suppress arrhythmias in injured hearts. Nature 489, 322-325. doi: 10.1038/nature11317

Spencer, F. A., Meyer, T. E., Goldberg, R. J., Yarzebski, J., Hatton, M., Lessard, D., et al. (1999). Twenty year trends (1975-1995) in the incidence, in-hospital and long-term death rates associated with heart failure complicating acute myocardial infarction: a community-wide perspective. J. Am. Coll. Cardiol. 34, 1378-1387. doi: 10.1016/S0735-1097(99)00390-3

Thomas, G. D. (2011). Neural control of the circulation. Adv. Physiol. Educ. 35, 28-32. doi: 10.1152/advan.00114.2010

Tomaselli, G. F., and Zipes, D. P. (2004). What causes sudden death in heart failure? Circ. Res. 95, 754-763. doi: 10.1161/01.RES.0000145047.14691.db 
Triposkiadis, F., Karayannis, G., Giamouzis, G., Skoularigis, J., Louridas, G., and Butler, J. (2009). The sympathetic nervous system in heart failure physiology, pathophysiology, and clinical implications. J. Am. Coll. Cardiol. 54, 1747-1762. doi: 10.1016/j.jacc.2009.05.015

Tu, H., Liu, J., Zhang, D., Zheng, H., Patel, K. P., Cornish, K. G., et al. (2014). Heart failure-induced changes of voltage-gated $\mathrm{Ca}^{2+}$ channels and cell excitability in rat cardiac postganglionic neurons. Am. J. Physiol. Cell. Physiol. 306, C132C142. doi: 10.1152/ajpcell.00223.2013

Tu, H., Zhang, L., Tran, T. P., Muelleman, R. L., and Li, Y. L. (2010). Reduced expression and activation of voltage-gated sodium channels contributes to blunted baroreflex sensitivity in heart failure rats. J. Neurosci. Res. 88, 3337-3349. doi: 10.1002/jnr.22483

Vaseghi, M., and Shivkumar, K. (2008). The role of the autonomic nervous system in sudden cardiac death. Prog. Cardiovasc. Dis. 50, 404-419. doi: $10.1016 /$ j.pcad.2008.01.003

Verrier, R. L., and Antzelevitch, C. (2004). Autonomic aspects of arrhythmogenesis: the enduring and the new. Curr. Opin. Cardiol. 19, 2-11. doi: 10.1097/00001573-200401000-00003

Wang, H. J., Wang, W., Cornish, K. G., Rozanski, G. J., and Zucker, I. H. (2014). Cardiac sympathetic afferent denervation attenuates cardiac remodeling and improves cardiovascular dysfunction in rats with heart failure. Hypertension 64, 745-755. doi: 10.1161/HYPERTENSIONAHA.114.03699

Watson, A. M., Hood, S. G., and May, C. N. (2006). Mechanisms of sympathetic activation in heart failure. Clin. Exp. Pharmacol. Physiol. 33, 1269-1274. doi: 10.1111/j.1440-1681.2006.04523.x

Wolk, M. J., Scheidt, S., and Killip, T. (1972). Heart failure complicating acute myocardial infarction. Circulation 45, 1125-1138. doi: 10.1161/01.CIR.45.5.1125

Xue, C., Hua, W., Cai, C., Ding, L. G., Liu, Z. M., Fan, X. H., et al. (2016). Acute and chronic changes and predictive value of Tpeak-Tend for ventricular arrhythmia risk in cardiac resynchronization therapy patients. Chin. Med. J. 129, 2204-2211. doi: 10.4103/0366-6999.189916

Yagishita, D., Chui, R. W., Yamakawa, K., Rajendran, P. S., Ajijola, O. A., Nakamura, K., et al. (2015). Sympathetic nerve stimulation, not circulating norepinephrine, modulates T-peak to T-end interval by increasing global dispersion of repolarization. Circ. Arrhythm. Electrophysiol. 8, 174-185. doi: 10.1161/CIRCEP.114.002195
Yamada, C., Kuwahara, K., Yamazaki, M., Nakagawa, Y., Nishikimi, T., Kinoshita, H., et al. (2016). The renin-angiotensin system promotes arrhythmogenic substrates and lethal arrhythmias in mice with nonischaemic cardiomyopathy. Cardiovasc. Res. 109, 162-173. doi: 10.1093/cvr/ cvv248

Yan, G. X., Lankipalli, R. S., Burke, J. F., Musco, S., and Kowey, P. R. (2003). Ventricular repolarization components on the electrocardiogram: cellular basis and clinical significance. J. Am. Coll. Cardiol. 42, 401-409. doi: 10.1016/S0735-1097(03)00713-7

Zhang, D., Liu, J., Tu, H., Muelleman, R. L., Cornish, K. G., and Li, Y. L. (2014). In vivo transfection of manganese superoxide dismutase gene or nuclear factor kappaB shRNA in nodose ganglia improves aortic baroreceptor function in heart failure rats. Hypertension 63, 88-95. doi: 10.1161/HYPERTENSIONAHA.113.02057

Zhang, D., Liu, J., Zheng, H., Tu, H., Muelleman, R. L., and Li, Y. L. (2015). Effect of angiotensin II on voltage-gated sodium currents in aortic baroreceptor neurons and arterial baroreflex sensitivity in heart failure rats. J. Hypertens. 33, 1401-1410. doi: 10.1097/HJH.0000000000000563

Zipes, D. P., and Rubart, M. (2006). Neural modulation of cardiac arrhythmias and sudden cardiac death. Heart Rhythm 3, 108-113. doi: 10.1016/j.hrthm.2005.09.021

Zuberi, Z., Nobles, M., Sebastian, S., Dyson, A., Lim, S. Y., Breckenridge, R., et al. (2010). Absence of the inhibitory G-protein Galphai2 predisposes to ventricular cardiac arrhythmia. Circ. Arrhythm. Electrophysiol. 3, 391-400. doi: 10.1161/CIRCEP.109.894329

Conflict of Interest Statement: The authors declare that the research was conducted in the absence of any commercial or financial relationships that could be construed as a potential conflict of interest.

Copyright (c) 2017 Zhang, Tu, Wang, Cao, Muelleman, Wadman and Li. This is an open-access article distributed under the terms of the Creative Commons Attribution License (CC BY). The use, distribution or reproduction in other forums is permitted, provided the original author(s) or licensor are credited and that the original publication in this journal is cited, in accordance with accepted academic practice. No use, distribution or reproduction is permitted which does not comply with these terms. 